\title{
The prevalence of work-related musculoskeletal disorders in long- distance bus drivers
}

\author{
N Rugbeer, ${ }^{1}$ M Sport Science; $\mathbf{N}$ Neveling, ${ }^{1}$ MSc Med; \\ T Sandla, 1 BTech Biokinetics \\ 1 Department of Sport, Rehabilitation and Dental Science, Tshwane \\ University of Technology, Pretoria, South Africa
}

Corresponding author: $N$ Rugbeer (Rugbeern@tut.ac.za)

Background: Work-related musculoskeletal disorders (WRMSDs) contribute to poor posture and prolonged stress and strain due to work demands and the environment.

Objective: The objective of the study was to determine the prevalence of WRMSDs in long-distance bus drivers.

Methods: A cross-sectional survey study was conducted to determine the prevalence of WRMSDs among male longdistance bus drivers. Eighty-nine participants were selected from a reputable bus company in Pretoria to participate in the study. The Nordic Musculoskeletal Questionnaire (NMQ) was used to determine self-reported WRMSDs.

Results: The average age of the participants was 45 years, with a mean height and weight of $1.69 \mathrm{~m}$ and $85.4 \mathrm{~kg}$ respectively. Participants in the study had a mean body mass index of $29.9 \mathrm{~kg} . \mathrm{m}^{-2}$, categorising them as overweight. From the bus drivers who reported WRMSDs due to driving (22\%), most of the pain was noted in the upper back (44\%), followed by lower back (42\%), neck (42\%), shoulder $(37 \%)$, and wrist/hand (31\%). A strong, positive association existed between ankle and knee pain using Kendall's tau-b correlation $(\tau b=.71, p=.0001)$. A moderate and positive association was further noted between pain in the neck/shoulder $(\tau b=.59, \mathrm{p}=.0001)$ and upper back/shoulder $(\tau \mathrm{b}=.59, \mathrm{p}=.0001)$.

Conclusion: The greatest proportion of pain was experienced along the axial skeleton in long-distance bus drivers. Upper back pain was the most prevalent of the WRMSDs reported in these drivers.

Keywords: maladroit postures; musculoskeletal pain; kinetic chain; axial skeleton; appendicular skeleton

S Afr J Sports Med 2016;28(2):55-58.DOI: 10.17159/2078-516X/2016/v28i2a1109

Work-related musculoskeletal disorders (WRMSDs) is defined as poor optimisation and functioning of multiple joints, muscles, tendons, nerves and bones due to the work environment.[1] WRMSDs are induced by postural defects, repetitive tasks, environmental factors, and prolonged stresses and strains experienced in long-distance driving. ${ }^{[2]}$ One of the consequences of these disorders is an increase in absenteeism, which places an economic strain on the employer and the employee. ${ }^{[3]}$

WRMSDs have become multifaceted and a global phenomenon, accounting for $42-48 \%$ of work-related musculoskeletal illnesses. ${ }^{[2]}$ Risk factors associated with
WRMSDs include uncomfortable seats, ${ }^{[4]}$ vibration exposure ${ }^{[5]}$ and maladroit postures. ${ }^{[6]}$

Long-distance driving involves repetitive tasks, such as handling, bending and prolonged sitting, which may place excessive stress along the kinetic chain and affect the driver's personal and social life. ${ }^{[2]}$ A study in Ghana revealed $71 \%$ of minibus drivers sustained WRMSDs. Lower back and upper back pain constituted $34 \%$ and $17 \%$ of injuries respectively. ${ }^{[1]}$

A recent international study revealed neck pain and upper limb WRMSDs were prevalent in bus drivers compared to other anatomical skeletal structures. ${ }^{[7]}$ Back and neck disorders were prominent in long-distance bus drivers. ${ }^{[8]}$ This was associated with chronic pain and early retirement. ${ }^{[8]}$ There are no data on WRMDs in long-distance drivers in South Africa. Therefore, the aim of this study is to determine the prevalence of WRMSDs among a sample of bus drivers employed at a bus company located in Tshwane, South Africa.

\section{Methods}

\section{Study design and procedure}

A descriptive survey study was conducted to determine the prevalence of WRMSDs among male long-distance bus drivers. Eighty-nine participants were selected to participate in the study. Participants were between the ages of 20 to 65 years, and were included in the study if they were permanent drivers, had a valid code $C$ drivers licence and at least nine years of experience. Participants were excluded if they had sustained musculoskeletal disorders from macro-traumatic incidents (e.g. motor vehicle accident, acute traumatic sports injury). Ethical clearance for this study was obtained from the Tshwane University of Technology, Faculty Committee for Research Ethics (FCRE 2015/06/013). The data were collected using the Nordic Musculoskeletal Questionnaire (NMQ) ${ }^{[9]}$ to investigate the prevalence of WRMSDs among the participants. The NMQ was chosen because of its widespread validity, and as a reliable cost-effective means of determining self-reported musculoskeletal disorders. ${ }^{[9]}$ The bus company assisted in drafting a roster of available participants and communicated the available times and dates to the researcher. The researcher was present on the available days to administer the questionnaire. The researcher was the translator, assisting the participants in understanding the purpose of the study and other aspects of the questionnaire. Each participant was requested to sign an informed consent form prior to the commencement of the study. The questionnaire was administered during their break time from driving, and the participants completed it in a private environment to ensure confidentiality. The participants were instructed not to write their names on the questionnaires, thereby ensuring anonymity. The completed questionnaires were placed in a large box for further analysis by the researcher. 


\section{Data analysis}

The descriptive characteristics of the long-distance bus drivers (frequency tables, means and standard deviations) were analysed using the Statistical Package for Social Science Version 18.0 (SPSS) for Windows to determine the prevalence and variance of WRMSDs. Kendall's tau-b was used to provide information regarding the strength of association between the various outcomes variables. The level of significance was set at $\mathrm{p} \leq 0.05$.

\section{Results}

A total of 89 long-distance bus drivers participated in the study. The mean age of the participants was 45 years. Their mean height and mass was $1.69 \mathrm{~m}$ and $85.4 \mathrm{~kg}$ respectively. Their body mass index was $29.9 \mathrm{~kg} \cdot \mathrm{m}^{-2}$, categorising them as overweight.

In this study, $77 \%$ of participants were married and $80 \%$ were non-smokers. The majority of the participants had completed secondary school education (60\%). The participants were well-experienced long-distance drivers; with $93 \%$ having five years and more experience. From the total number of participants in the study $(n=89)$, a large percentage of participants (38\%) drive for more than 12 hours at a time. Only $22 \%$ of all participants $(n=89)$ selfreported WRMSDs as a result of driving. Paradoxically, $67 \%$ of the 89 participants indicated that they do experience symptoms of WRMSDs as a result of driving (Table 1). Pain was the common symptom (73\%) experience by the participants (Table 1). When the responses of the bus drivers who reported WRMSDs (22\%) were analysed, the greatest discomfort or pain was in the upper back (44\%), lower back (42\%), neck (42\%), shoulder (37\%), and wrist/hand (31\%) (Figure 1). Minimal pain and discomfort was evident in the elbow (20\%), hips/thighs (24\%), knees (23\%), and ankle (24 $\%)$ (Figure 1).

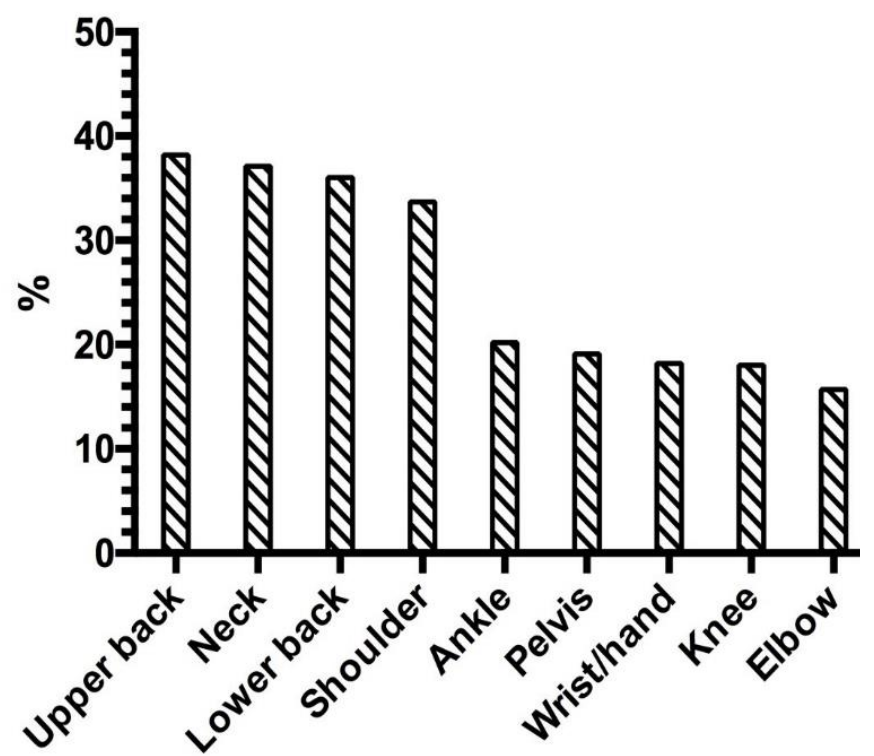

Fig. 1: Prevalence of region of pain in long-distance bus drivers who has reported WRMSD
Table 1. Occupational profile of participants

\begin{tabular}{|c|c|}
\hline Characteristics & $\mathbf{N}(\%)$ \\
\hline Males & $89(100)$ \\
\hline \multicolumn{2}{|l|}{ Marital status } \\
\hline Married & $68(77)$ \\
\hline Divorced & $5(6)$ \\
\hline Never Married & $15(17)$ \\
\hline \multicolumn{2}{|l|}{ Smoking History } \\
\hline Smoker & $9(10)$ \\
\hline Non Smoker & $70(80)$ \\
\hline Ex-Smoker & $9(10)$ \\
\hline \multicolumn{2}{|c|}{ What Level of education was completed? } \\
\hline Primary School Complete & $2(2)$ \\
\hline Secondary School Complete & $52(60)$ \\
\hline Higher Degree Completed & $32(37)$ \\
\hline Bachelor Degree and above & $1(1)$ \\
\hline \multicolumn{2}{|c|}{ How long have you been driving? } \\
\hline$<5$ years & $6(7)$ \\
\hline 5 years and more & $83(93)$ \\
\hline \multicolumn{2}{|c|}{ Which type of vehicle do you drive? } \\
\hline 5 Ton & $2(2)$ \\
\hline$>5$ Ton & $87(98)$ \\
\hline \multicolumn{2}{|c|}{ How much of time you drive daily? } \\
\hline Less than 8 hours & $11(12)$ \\
\hline 8-10 hours & $25(28)$ \\
\hline 10-12hours & $19(21)$ \\
\hline More than 12 hours & $34(38)$ \\
\hline \multicolumn{2}{|c|}{ Is there vibration exposure during driving? } \\
\hline Yes & $24(28)$ \\
\hline No & $62(72)$ \\
\hline \multicolumn{2}{|c|}{$\begin{array}{l}\text { Have you had any musculoskeletal disorder due to } \\
\text { driving? }\end{array}$} \\
\hline Yes & $19(22)$ \\
\hline No & $69(78)$ \\
\hline \multicolumn{2}{|c|}{ Do you experience symptoms? } \\
\hline Yes & $60(67)$ \\
\hline No & $29(33)$ \\
\hline \multicolumn{2}{|c|}{ What word best describes your symptoms? } \\
\hline Pain & $44(73)$ \\
\hline Ache & $7(12)$ \\
\hline Cramp & $5(8)$ \\
\hline Stiffness & $4(7)$ \\
\hline
\end{tabular}

There was a weak, positive correlation between musculoskeletal disorders and body mass index (BMI), which was not statistically significant $(\tau b=.13, p=.14)$. A weak correlation was further noted between WRMSDs and vibration exposure $(\tau b=.25)$, seat comfort $(\tau b=-.25)$, and driving duration $(\tau b=.06)$. There was a strong, positive correlation between ankle discomfort and knee pain, which was statistically significant ( $\tau b=.71, p=.0001)$. A moderate correlation existed between pain in neck/shoulder, upper back/shoulder, lower back/pelvis and elbow/wrist (Table 2).

\section{Discussion}

The first finding of this study was that the most prevalent 
Table 2. Association between WRMSD and various outcome measurements

\begin{tabular}{|c|c|c|c|}
\hline Variable & Number & $\begin{array}{l}\text { Correlation } \\
\text { Coefficient }\end{array}$ & $\begin{array}{c}\text { Significance } \\
(\mathrm{p})\end{array}$ \\
\hline $\begin{array}{l}\text { WRMSD and } \\
\text { BMI }\end{array}$ & 88 & .13 & .14 \\
\hline $\begin{array}{l}\text { WRMSD and } \\
\text { Vibration } \\
\text { Exposure }\end{array}$ & 86 & .25 & .02 \\
\hline $\begin{array}{l}\text { WRMSD and } \\
\text { Seat comfort }\end{array}$ & 87 & -.25 & .02 \\
\hline $\begin{array}{l}\text { WRMSD and } \\
\text { Driving } \\
\text { duration }\end{array}$ & 88 & .06 & .52 \\
\hline $\begin{array}{l}\text { Ankle and } \\
\text { Knee }\end{array}$ & 89 & .71 & ${ }^{*} .0001$ \\
\hline $\begin{array}{l}\text { Neck and } \\
\text { shoulder }\end{array}$ & 89 & .60 & ${ }^{*} .0001$ \\
\hline $\begin{array}{l}\text { Upper Back } \\
\text { and shoulder }\end{array}$ & 89 & .59 & *.0001 \\
\hline $\begin{array}{l}\text { Lower back } \\
\text { and pelvis }\end{array}$ & 89 & .53 & ${ }^{*} .0001$ \\
\hline $\begin{array}{l}\text { Elbow and } \\
\text { wrist/hand }\end{array}$ & 89 & .58 & *.0001 \\
\hline
\end{tabular}

Note: Work-related musculoskeletal disorders (WRMSDs) $\mathrm{r} \leq .3$ weak correlation, $.3>\mathrm{r} \leq .7$ moderate correlation, $\mathrm{r}>0.7$ strong correlation

Significance ${ }^{*} \mathrm{p} \leq .05$

WRMSDs were upper back followed by neck, lower back, shoulders, ankle, pelvis, wrist/hand, knee and elbows. This finding is similar to that found in a study conducted in Ghana [1], which concluded the most prevalent WRMSDs were lower and upper back. Therefore, the current study creates an awareness that upper back disorders are highly prevalent among bus drivers in South Africa.

The next finding was that there was a mismatch between reported WRMSDs and symptoms experienced due to driving. Several drivers reported no WRMSDs due to their driving; however, they reported experiencing symptoms, particularly pain, after driving. This suggests that WRMSDs are masquerading as symptoms experienced by drivers.

Several bus drivers were overweight. The low correlation between BMI and WRMDs suggests factors other than being overweight were associated with WRMDs. However, an elevated BMI predisposes one to cardiovascular disease [10] and road accidents. [11] An elevated BMI predisposes bus drivers to a slumped seated posture, contributing to muscle imbalance and pain. ${ }^{[12]}$ Cardiovascular disease, especially hypertension, is prevalent in long-distance bus drivers. This is due to poor lifestyle choices adopted by drivers, such as irregular eating habits, sitting for prolonged periods and low physical activity. ${ }^{[10]}$ Although not investigated in this study, interventions targeted at reducing BMI may assist in reducing the risk of cardiovascular disease and road accidents.

A moderate correlation between pain in the neck and shoulders and upper back and shoulders were noted in longdistance bus drivers. Excessive protrusion of the neck may narrow and degenerate the intervertebral foramen predisposing drivers to neurological pathology. ${ }^{[13]}$ Upper Crossed Syndrome is characterised by the hypertonic upper trapezius, levator scapulae, and pectoralis muscles, as well as inhibition of the deep cervical flexors, rhomboids, and serratus anterior, which may affect scapulothoracic joint movement. ${ }^{[14]}$ As a result of this muscle imbalance, inadequate function of the scapulothoracic and glenohumeral joints may lead to superior humeral elevation and poor neuromuscular control.[15], thus predisposing the drivers to secondary impingement syndrome.

As a result of prolonged sitting the iliopsoas muscle may become hypertonic, resulting in reciprocal inhibition of deep abdominal, interspinous, and gluteus muscle groups contributing to reduced stability and extensor mechanism dysfunction.[16] This may increase the risk of mechanical, lower back pain in long-distance bus drivers. Longitudinal intervention studies, incorporating these associations in a physical therapy plan targeted at long-distance drivers, will preserve function, improve efficiency and reduce the incidence of musculoskeletal pathology.

\section{Conclusion}

Upper back pain was the most prevalent WRMSD in longdistance bus drivers residing in Tshwane. Bus drivers were unware that the underlying symptoms experienced due to driving may be masquerading as WRMDs. This often prevented them from seeking medical attention.

Several bus drivers were overweight. Elevated BMI may predispose drivers to an increased risk of cardiovascular disease and road accidents. Future intervention studies should consider the association and the interrelationship between various muscle groups and their effect on joint function. These studies should also incorporate these associations in a physical therapy/rehabilitation plan targeted at long-distance drivers.

Acknowledgements: Tshwane University of Technology and the bus company for granting us permission to conduct the research.

\section{Conflict of interest: No conflict of interest}

\section{References}

1. Abledu JK, Offei EB, Abledu GK. Occupational and personal determinants of musculoskeletal disorders among urban taxi drivers in Ghana. Int Sch Res Notices 2014; 2014:517259. [http://dx.doi.org/10.1155/2014/517259] [PMID: 27379297]

2. Magnavita N, Elovainio M, De Nardis I,et al. Environmental discomfort and musculoskeletal disorders. Occup Med (Lond) 2011;61(3):196-201. [http://dx.doi.org/10.1093/occmed/kqr024] [PMID: 21525071]

3. Guo HR, Chang YC, Yeh WY, et al. Prevalence of musculoskeletal disorder among workers in Taiwan: a nationwide study. J Occup 
Health 2004;46(1):26-36. [http://dx.doi.org/10.1539/joh.46.26] [PMID: 14960827]

4. Alperovitch-Najenson D, Katz-Leurer M, Santo Y, et al. Upper body quadrant pain in bus drivers. Arch Environ Occup Health 2010;65(4):218-223. [http://dx.doi.org/10.1080/19338244.2010.486422] [PMID: 20450125]

5. Bovenzi M. Metrics of whole-body vibration and exposure-response relationship for low back pain in professional drivers: a prospective cohort study. Int Arch Occup Environ Health 2009;82(7):893-917. [http://dx.doi.org/10.1007/s00420-008-0376-3] [PMID: 18953559]

6. Albert WJ, Everson D, Rae M, et al. Biomechanical and ergonomic assessment of urban transit operators. Work 2014;47(1):33-44. [http://dx.doi.org/10.3233/WOR-131683] [PMID: 24004743]

7. Rugulies R, Krause N. Effort-reward imbalance and incidence of low back and neck injuries in San Francisco transit operators. Occup Environ Med 2008;65(8):525-533

[http://dx.doi.org/10.1136/oem.2007.035188] [PMID: 18056748]

8. Okunribido OO, Shimbles SJ, Magnusson M, et al. City bus driving and low back pain: a study of the exposures to posture demands, manual materials handling and whole-body vibration. Appl Ergon 2007;38(1):29-38. [http://dx.doi.org/10.1016/j.apergo.2006.01.006] [PMID: 17225292]

9. de Barros EN, Alexandre NM. Cross-cultural adaptation of the Nordic musculoskeletal questionnaire. Int Nurs Rev 2003;50(2):101-108. [http://dx.doi.org/10.1046/j.1466-7657.2003.00188.x] [PMID: 12752909]
10. Shin SY, Lee CG, Song HS, et al. Cardiovascular disease risk of bus drivers in a city of Korea. Ann Occup Environ Med 2013;25(1):34. [ http://dx.doi.org/10.1186/2052-4374-25-34] [PMID: 24472511]

11. Wiegand DM, Hanowski RJ, McDonald SE. Commercial drivers health: a naturalistic study of body mass index, fatigue, and involvement in safety-critical events. Traffic Inj Prev 2009;10(6):573579. [http://dx.doi.org/10.1080/15389580903295277] [PMID: 19916128]

12. Dabrh AMA, Firwana B, Cowl CT, et al. Health assessment of commercial drivers: a meta-narrative systematic review. BMJ Open 2014;4: e003434. [http://dx.doi.org/10.1136/bmjopen-2013-003434] [PMID: 24604478]

13. Jackson R. The classic: the cervical syndrome. Clin Orthop Relat Res 2010;468(7):1739-1745. [http://dx.doi.org/10.1007/s11999-010-1278-8] [PMID: 20177837]

14. Page $P$, Frank C, Lardner R. Assessment and treatment of muscle imbalance: the Janda approach. 1st ed. United States: Human Kinetics, 2010: 175-213.

15. Celik D, Sirmen B, Demirhan M. The relationship of muscle strength and pain in subacromial impingement syndrome. Acta Orthop Traumatol Turc 2011;45(2):79-84. [http://dx.doi.org/10.3944/aott.2011.2425] [PMID: 21610305]

16. Prentice WE. Rehabilitation Techniques for Sports Medicine and Athletic Training. 6th ed. Boston: Slack Incorporated, 2015:127- 